enable us as a community to care for these patients, while leaving well-staffed beds and surgical facilities in acute hospitals for those recently injured.

I thank the ward sisters, social workers, occupational therapists, and physiotherapists for the help given to me and to the patients, without which this study would have been impossible.

\section{References}

1 Office of Health Economics, The Cost of the NHS, information sheet No 24. London, OHE, 1974.

2 Dent, N A, Looking to Hospital: Ill Health in Bristol, No 19, p 1. Bristol, MOH for City and County of Bristol, 1973.

${ }^{3}$ Hunt, L B, British Medical fournal, 1973, 4, suppl p 83.

4 Registrar General's Statistical Review of England and Wales 1972, Part II, Tables Population. London, HMSO, 1974.

\title{
Radiology and endoscopy in acute upper gastrointestinal bleeding
}

\author{
G M FRASER， R N RANKIN， D H CUMMACK
}

British Medical fournal, 1976, 1, 270-271

\begin{abstract}
Summary
Of 112 patients admitted with acute upper gastrointestinal bleeding, the presumed bleeding site was detected in $61.5 \%$ of cases by radiology and in $\mathbf{5 7} \%$ of cases on endoscopy. Thirty-one patients who had barium-meal examination were operated on and the surgical and radiological findings agreed in $26(84 \%)$. Twenty-three patients who had endoscopy were operated on and the surgical and endoscopic findings agreed in $15(65 \%)$. In 10 cases radiology detected a lesion not identified on endoscopy and in nine endoscopy detected a lesion not seen at radiology. We suggest that when there are two potential sources of bleeding radiology as well as endoscopy can detect the actively bleeding lesion. The supplementary nature of radiology and endoscopy is emphasised and we conclude that both methods should be used if there is any doubt at the initial radiological or endoscopic examination about the source of the bleeding.
\end{abstract}

\section{Introduction}

Recently many reports have compared favourably the value of fibreoptic panendoscopy in acute upper gastrointestinal bleeding with emergency barium meal. ${ }^{1-5}$ As we did not think that the results of endoscopy have been so much better than those of barium-meal examination, we have compared fibreoptic endoscopy and emergency barium-meal examination in detecting the bleeding site in patients with either haematemesis or melaena admitted to this hospital in the four years 1971-4.

\section{Patients and methods}

Of the 112 patients, admitted (82 with haematemesis and 30 with melaena) 101 patients had barium-meal examination and 72 patients endoscopy. Both barium-meal examination and endoscopy were performed in 61 cases, barium meal alone in 40 cases, and endo-

Department of Radiodiagnosis, Western General Hospital, Edinburgh EH4 2XU

G M FRASER, MB, FRCR, consultant radiologist

$R$ N RANKIN, MB, DMRD, registrar in radiodiagnosis (present address : Department of Radiodiagnosis, University Hospital, London, Ontario, Canada)

D H CUMMACK, MB, FRCR, consultant radiologist scopy alone in 11 cases. We recorded those cases in which a potential bleeding lesion was detected by either radiology or endoscopy. Such a lesion was deemed to be present whether or not it was seen by the alternative method of examination, unless it was subsequently disproved at operation. The radiological opinion given at the time of the examination was used in the analysis of the results even if a subsequent review of the films revealed a lesion not initially reported.

An uncomplicated hiatus hernia seen either at endoscopy or barium meal and a deformed duodenal cap without active ulceration seen at barium-meal examination were not regarded as potential sources of bleeding. Similarly, gastritis and duodenitis seen at endoscopy were not considered to be potential bleeding sources unless superficial erosions, frank bleeding, or blood clot were present.

\section{Results}

A diagnosis was made in $62\left(61.5^{\circ}\right)$ of the 101 patients who had barium-meal examination and in $41(57 \%)$ of the 72 patients who had endoscopy. Employing either or both methods a diagnosis was made in 80 patients out of $112(71 \%)$. Chronic gastric and duodenal ulcers were responsible for most cases of bleeding, accounting for 60 of the 80 cases $\left(75^{\circ}\right)$ in which there was a final diagnosis. No case of erosive gastritis was detected by radiology whereas 6 of the 72 cases $(8 \%)$ who had endoscopy were found to have gastric erosions.

Of the 112 patients 35 were operated on and we compared the surgical radiological, and endoscopic findings. Of these 31 had a barium-meal examination and in 26 of these $(84 \%)$ there was radiological and surgical agreement. In four cases a surgically detected lesion had not been seen at barium meal and one patient had a presumed falsepositive radiological finding. Twenty-three of the operated patients underwent endoscopy and in $15(65 \%)$ the endoscopic and surgical findings agreed. In six cases a surgically detected lesion had not been seen at endoscopy and two patients had a presumed endoscopic falsepositive finding.

In 10 cases the presumed bleeding lesion was detected by radiology but not seen at endoscopy and in half of these the radiological diagnosis was confirmed surgically. In nine cases the probable bleeding lesion was detected by endoscopy but not seen at radiology. There was surgical confirmation of the endoscopic findings in one patient and in another patient with a concomitant duodenal ulcer oesophageal varices were seen to be the bleeding site at endoscopy. The oesophageal varices were not seen at barium meal.

Active bleeding or blood clot in or adjacent to a lesion, thus identifying the bleeding point, was seen at barium-meal examination in 13 cases and at endoscopy in eight. In six cases multiple lesions were seen at barium-meal examination and the lesion responsible for the bleeding was identified by a blood clot in one. Five cases with multiple lesions were seen at endoscopy and the lesion responsible for the bleeding was identified in two.

\section{Discussion}

A positive diagnosis was made at endoscopy in this series in 
Presumed bleeding lesion in 112 cases, showing method of detection, either by barium meal or endoscopy, number of cases surgically confirmed, and number of cases in which the bleeding point was identified

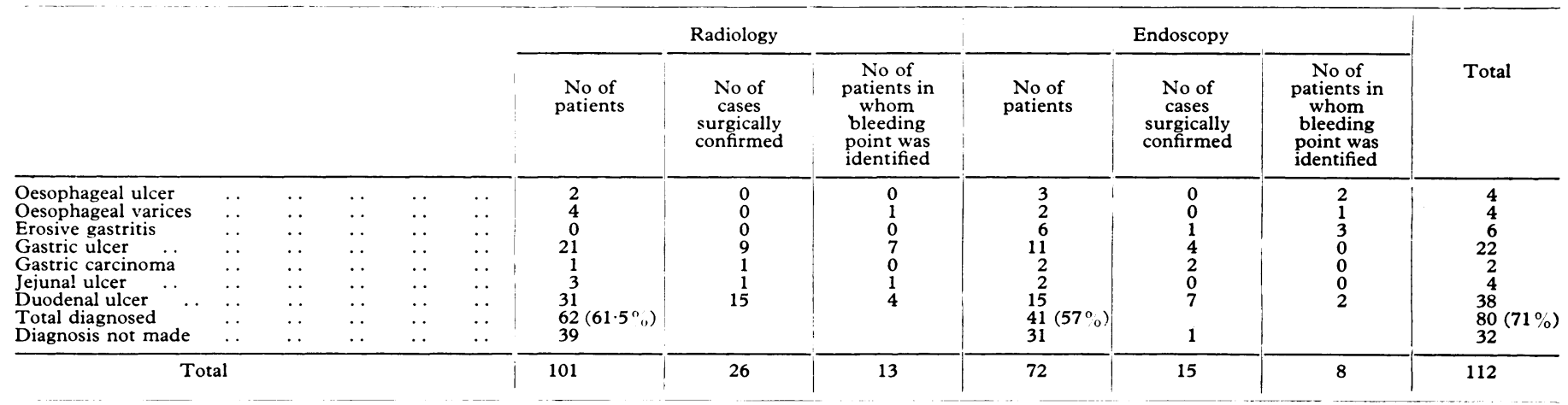

$57 \%$ of cases and at barium-meal examination in $61.5 \%$. The surgical findings agreed with the endoscopic findings in 15 out of 23 cases and with the barium-meal findings in 26 out of 31. By implication, therefore, in those cases where there was no such available correlation there was no evidence that the barium-meal examination was in any way less reliable than endoscopy. These findings do not agree with those recently published where the accuracy of endoscopy has been much higher and that of radiology much lower. McGinn and Wilken ${ }^{6}$ made a positive diagnosis at endoscopy in $76^{\circ}$ of cases whereas barium-meal examination had been accurate in only $41^{\circ}{ }_{0}$. The respective accuracy of endoscopy and radiology given by other authors are endoscopy $90^{\circ}{ }_{0}$ and radiology $32 \%,{ }^{3}$ endoscopy $92 \%$ and radiology $30 \%,{ }^{\circ}$ endoscopy $96 \%$ and radiology $39 \%,{ }^{5}$ and endoscopy $97 \%$ and radiology $34 \%{ }^{\circ} .^{2}$ The poor performance of barium-meal examination is surprising in view of the much higher accuracy recorded by earlier authors, who detected the bleeding site by barium-meal examination in $67^{\circ}$ o to $76^{\circ}{ }_{0}$ of cases. ${ }^{7-10}$ It is difficult to find a satisfactory explanation for this apparent marked deterioration in the accuracy of the barium-meal findings with the passage of time.

Some authors ${ }^{511} 12$ make the point that the actual bleeding site may be identified at endoscopy and that if there are two potential bleeding sources it is impossible for the radiologist to tell which lesion is responsible. This, in our view, is a misconception. We identified the bleeding point at barium meal in 13 patients, either because of the presence of blood clot in or adjacent to an ulcer crater or because of a characteristic fluffy appearance or flow effect of the barium, which fails to coat the mucosa in the presence of active bleeding. ${ }^{13} 14$

The reported incidence of multiple lesions seen at endoscopy varies from $4 \%{ }^{15}$ to $43 \%{ }^{2}$ Multiple lesions did not present an appreciable problem. In six patients $(6 \%)$ multiple lesions were seen on barium-meal examination, in one of which a clot adjacent to an ulcer identified the bleeding lesion, and five $(7 \%)$ were seen on endoscopy, in two of which the lesion responsible was seen to be bleeding.

Erosive gastritis was diagnosed in six out of 72 patients on endoscopy and in none of the barium-meal examinations. In this we agree with other authors ${ }^{16}$ that barium-meal examination is a notably unreliable method of detecting superficial lesions such as gastric erosions, but the 10 cases of chronic peptic ulcer diagnosed at barium-meal examination and not seen at endoscopy is inescapable evidence of the value of emergency barium-meal examination. An accuracy rate of $61.5 \%$ at barium-meal examination and $57 \%$ at endoscopy leaves little room for complacency for either the radiologist or endoscopist and an overall accuracy rate of $71 \%$ using either or both methods only emphasises the supplementary nature of the two methods of examination.

Whether radiology or endoscopy is used as the routine method of investigation is a matter of choice for the doctor responsible for the patient, but the findings in this series indicate that both methods should be used if the lesion responsible for the bleeding has not been discovered beyond doubt by the first method of approach.

We are grateful to the physicians and surgeons of the Western General Hospital whose patients we studied in this series and in particular to Mr W P Small for his helpful advice and criticism.

\section{References}

${ }^{1}$ Katon, R M, and Smith, F W, Gastroenterology, 1973, 65, 728.

2 Sugawa, C, et al, Archives of Surgery, 1973, 107, 133.

${ }^{3}$ Allen, H M, et al, Archives of Surgery, 1973, 106, 450.

${ }^{4}$ Cotton, P B, et al, British Medical fournal, 1973, 2, 505.

${ }^{5}$ Hoare, A M, British Medical fournal, 1975, 1, 27.

${ }^{6} \mathrm{McGinn}, \mathrm{F}$ P, and Wilken, B J, Fournal of the Royal College of Surgeons of Edinburgh, 1974, 19, 112.

7 Knowles, H C, et al, Radiology, 1952, 58, 536.

${ }^{8}$ Zamcheck, N, et al, American fournal of Medicine, 1952, 13, 713.

9 Elmer, R A, et al, Gastroenterology, 1950, 16, 552.

${ }_{10}$ Schatzki, S C, and Blade, W R, New England fournal of Medicine, 1958, $259,910$.

11 Forrest, J A H, et al, Lancet, 1974, 2, 394.

12 Waldram, R, et al, British Medical fournal, 1974, 4, 94.

${ }_{13}$ Cummack, D H, Gastrointestinal x-ray Diagnosis, p 4 . Edinburgh and London, E and S Livingstone, 1969.

14 Scott-Harden, W G, British Fournal of Hospital Medicine, 1973, 10, 149.

15 Seifert, E, et al, Urgent Endoscopy of Digestive and Abdominal Diseases, ed Z Mararka and J Setka, p 61. Basel, S Karger, 1972.

${ }^{16}$ British Medical fournal, 1974, 1, 609.
Do androgens or any other hormone treatments improve the memory in middle-aged men in addition to perhaps affecting their potency?

This query raises several interesting questions; none perhaps capable of direct answer. The suggestion is not as far-fetched as it might seem at first sight. Undoubtedly replacement treatment with gonadal hormones will control hot flushes in menopausal women and it is suggested that they also benefit many other symptoms which afflict women at this age. A poor memory is noted among menopausal symptoms in many textbooks. If oestrogens will give peace of mind and improve the memory of a menopausal woman, why should not testosterone do the same for man ? Of course, the hypothesis is wellnigh impossible to prove or disprove-which makes it all the more attractive in some quarters. Testosterone does not necessarily improve potency in the man. Potency is the result of many factors, among which declining testosterone production with advancing age may be a minor one. Certainly testosterone has a more direct effect on the woman's libido than any other hormone, but for both sexes sex is more in the head than in the gonads. Testosterone is more reliable as a protein anabolic agent than as a rejuvenator. Possibly some middleaged men will benefit from treatment with testosterone and it is unlikely that they will be harmed. Why not try it ? 